\section{D) Check for updates}

Cite this: Dalton Trans., 2017, 46 5202

Received 14th February 2017, Accepted 17th March 2017

DOI: $10.1039 / \mathrm{c} 7 \mathrm{dt} 00552 \mathrm{k}$ rsc.li/dalton

\title{
Synthesis of coenzyme $Q_{0}$ through divanadium- catalyzed oxidation of 3,4,5-trimethoxytoluene with hydrogen peroxide $\uparrow$
}

\author{
Olga V. Zalomaeva, (D) a Vasilii Yu. Evtushok, (D) a,b Gennadii M. Maksimov, (D) a \\ Raisa I. Maksimovskaya (D) a and Oxana A. Kholdeeva (D)*a,b
}

\begin{abstract}
The selective oxidation of methoxy/methyl-substituted arenes to the corresponding benzoquinones has been first realized using aqueous hydrogen peroxide as a green oxidant, acid tetrabutylammonium salts of the $\gamma$-Keggin divanadium-substituted phosphotungstate $\left[\gamma-\mathrm{PW}_{10} \mathrm{O}_{38} \mathrm{~V}_{2}(\mu-\mathrm{O})_{2}\right]^{5-}$ (I) as a catalyst, and $\mathrm{MeCN}$ as a solvent. The presence of the dioxovanadium core in the catalyst is crucial for the catalytic performance. The reaction requires an acid co-catalyst or, alternatively, a highly protonated form of I can be prepared and employed. The industrially relevant oxidation of 3,4,5-trimethoxytoluene gives 2,3dimethoxy-5-methyl-1,4-benzoquinone (ubiquinone 0 or coenzyme $Q_{0}$, the key intermediate for coenzyme $Q_{10}$ and other essential biologically active compounds) with $73 \%$ selectivity at $76 \%$ arene conversion. The catalyst retains its structure under turnover conditions and can be easily recycled and reused without significant loss of activity and selectivity.
\end{abstract}

\section{Introduction}

The selective aromatic oxidation of arenes bearing methoxy and methyl substituents offers an efficient access to a range of benzoquinones, which play an important role in biological systems and are useful intermediates in the synthesis of fine chemicals, nutraceuticals and pharmaceuticals. ${ }^{1}$ Ubiquinones (also called coenzymes $\mathrm{Q}_{n}$, among which $\mathrm{Q}_{10}$ is the most known coenzyme) act as biochemical oxidizing agents that mediate electron-transfer processes involved in energy production. $^{2,3}$ Their synthetic analogue, idebenone, has been developed as a drug for the treatment of Alzheimer's disease and other cognitive defects. ${ }^{4}$ 2,3-Dimethoxy-5-methyl-1,4benzoquinone, known as ubiquinone 0 or coenzyme $\mathrm{Q}_{0}$ $\left(\mathrm{CoQ}_{0}\right)$, can serve as a key intermediate in the synthesis of coenzyme $\mathrm{Q}_{10}$ and other ubiquinones (Scheme 1). ${ }^{5,6}$

The selective oxidation of methoxytoluenes to the corresponding $p$-benzoquinones can be accomplished using dimethyldioxirane as an oxidant, mineral acid as a catalyst and acetone as a solvent. ${ }^{7}$ Several synthetic methods were reported for the production of $\mathrm{CoQ}_{0}$ through the oxidation of commercially available 3,4,5-trimethoxytoluene (TMT) with the green

\footnotetext{
${ }^{a}$ Boreskov Institute of Catalysis, Pr. Ac. Lavrentieva 5, Novosibirsk 630090, Russia. E-mail: khold@catalysis.ru; Fax: +7-383-330-9573; Tel: +7-383-326-9433

${ }^{b}$ Novosibirsk State University, Pirogova str. 2, Novosibirsk 630090, Russia $\dagger$ Electronic supplementary information (ESI) available: FTIR, NMR and potentiometric titration data. See DOI: $10.1039 / \mathrm{c} 7 \mathrm{dt} 00552 \mathrm{k}$
}

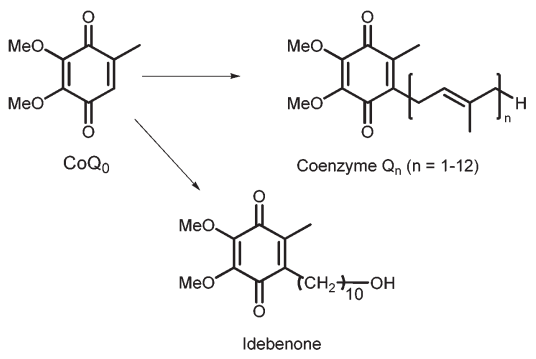

Scheme 1 Bioactive compounds derived from $\mathrm{CoQ}_{0}$.

oxidant - hydrogen peroxide. ${ }^{8-16}$ Among catalysts applied were potassium hexacyanoferrate(III), ${ }^{8}$ methyltrioxorhenium(VII) (MTORe), ${ }^{11,12}$ mineral acids $\left(\mathrm{H}_{2} \mathrm{SO}_{4}{ }^{10,16}\right.$ or $\left.\mathrm{HNO}_{3}{ }^{15}\right)$, and heteropolyacids of the general formula $\mathrm{H}_{n} \mathrm{XM}_{12} \mathrm{O}_{40}$ (where $\mathrm{X}=\mathrm{P}$ or $\mathrm{Si}, n=3(\mathrm{P})$ or $4(\mathrm{Si})$, and $\mathrm{M}=\mathrm{Mo}$ or $\mathrm{W}) \cdot{ }^{13,14}$ So far, the best yields of $\mathrm{CoQ}_{0}$ have been claimed for systems that employed formic acid as a solvent and phosphomolybdic heteropolyacid as a catalyst ${ }^{14}$ or a mixture of acetic and formic acids without any catalysts. ${ }^{16}$ However, the use of hydrogen peroxide in combination with carboxylic acids imposes practical problems related to reactor corrosion and safety risks associated with the in situ formation of explosive peroxy acids. Growing environmental concerns stimulated the development of more safe and sustainable catalytic methods for the production of methoxysubstituted $p$-benzoquinones. ${ }^{1 d, 17,18}$ 


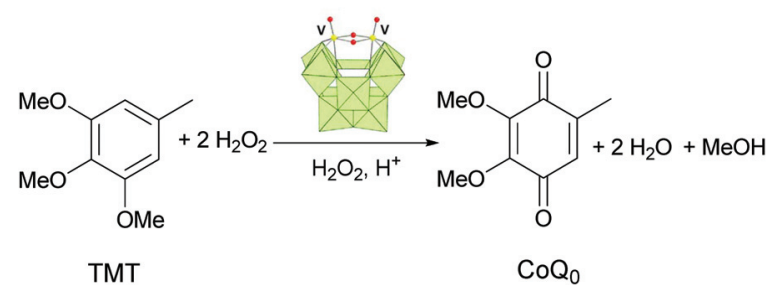

Scheme 2 Oxidation of TMT in the presence of $\mathrm{TBA}_{5-n} \mathrm{H}_{n}-\mathrm{I}$.

In 2012, Mizuno and co-workers discovered an efficient system for hydroxylation of arenes that involved the divanadiumsubstituted $\gamma$-Keggin phosphotungstate $\left(\mathrm{Bu}_{4} \mathrm{~N}\right)_{4}\left[\gamma-\mathrm{PW}_{10} \mathrm{O}_{38} \mathrm{~V}_{2}(\mu-\mathrm{O})\right.$ $(\mu-\mathrm{OH})]$ (hereinafter, $\left.\mathrm{TBA}_{4} \mathrm{H}-\mathrm{I}\right)$ as a catalyst, mineral acid as a co-catalyst, $\mathrm{H}_{2} \mathrm{O}_{2}$ as an oxidant, and $\mathrm{MeCN} / t-\mathrm{BuOH}(1: 1)$ as a solvent. ${ }^{19}$ At a substrate to oxidant ratio of 50, mono- and dialkyl(alkoxy)arenes afforded the corresponding phenols with excellent chemoselectivity and unusual regioselectivity. More recently, we investigated the catalytic performance of $\mathrm{TBA}_{4} \mathrm{H}-\mathrm{I}$ in some industrially important reactions, such as oxidation of 2,3,6-trimethylphenol (TMP) ${ }^{20}$ and pseudocumene ${ }^{21}$ to 2,3,5trimethyl- $p$-benzoquinone (TMBQ, Vitamin E precursor) using $\mathrm{H}_{2} \mathrm{O}_{2}$, and found that TMP can be converted to TMBQ with a nearly quantitative yield and $80-90 \%$ oxidant utilization efficiency. ${ }^{20}$ In contrast to the oxidation of alkylarenes, this reaction did not require an acid co-catalyst.

In the present work, we explored further the catalytic properties of $\mathrm{TBA}_{5-n} \mathrm{H}_{n}$-I $(n=1-2)$ in $\mathrm{H}_{2} \mathrm{O}_{2}$-based aromatic oxidation and first employed this catalyst system to accomplish the challenging oxidative transformation of TMT into coenzyme $\mathrm{Q}_{0}$ (Scheme 2). The extension of this method toward other methoxyarenes is also reported. We carefully investigated the role of the acid co-catalyst and a possibility to replace it by using a highly protonated form of I. The catalyst stability and recyclability issues have also been addressed.

\section{Results}

In most procedures reported in the literature for TMT oxidation with $\mathrm{H}_{2} \mathrm{O}_{2}$, the reaction proceeds in acidic medium, such as acetic or formic acid. ${ }^{9-11,13,15,16}$ Some of them require addition of mineral acid in catalytic amounts to accelerate the formation of peroxy acid, which is the real oxidizing species in these systems. ${ }^{10,15,16}$ In view of our interest in the development of a more safe and environmentally friendly approach to the synthesis of $\mathrm{CoQ}_{0}$, we have checked whether a mineral acid can play a role of the sole catalyst in a less corrosive and harmful solvent, for example, MeCN. While TMT conversion was negligible without any catalyst (Table 1 , entry 1 ), in the presence of $\mathrm{HClO}_{4}$, it attained $22 \%$ after $40 \mathrm{~min}$ at $60{ }^{\circ} \mathrm{C}$. However, selectivity toward the target product was low (Table 1 , entry 2 ) and the yield of $\mathrm{CoQ}_{0}$ did not exceed $4 \%$.

Previously, the group of Mizuno demonstrated that efficient hydroxylation of arenes can be realized in the presence of the
Table 1 TMT oxidation with $\mathrm{H}_{2} \mathrm{O}_{2}$ in the presence of $\mathrm{HClO}_{4}$ and $\mathrm{I}^{a}$

\begin{tabular}{llllll}
\hline Entry & $\begin{array}{l}\mathrm{TBA}_{3.5} \mathrm{H}_{1.5}-\mathrm{I} \\
(\mathrm{mM})\end{array}$ & $\begin{array}{l}\mathrm{HClO}_{4} \\
(\mathrm{mM})\end{array}$ & $\begin{array}{l}\text { Time } \\
(\mathrm{min})\end{array}$ & $\begin{array}{l}\text { TMT } \\
\text { conv. (\%) }\end{array}$ & $\left.\begin{array}{l}\mathrm{CoQ}_{0} \\
\text { select. }\end{array}{ }^{b} \%\right)$
\end{tabular}

${ }^{a}$ Reaction conditions: TMT $(0.1 \mathrm{M}), \mathrm{H}_{2} \mathrm{O}_{2}(0.2 \mathrm{M}), \mathrm{MeCN} 1 \mathrm{~mL}, 60^{\circ} \mathrm{C}$. ${ }^{b}$ Yield based on converted TMT.

divanadium-substituted polyoxometalate (POM) $\mathrm{TBA}_{4} \mathrm{H}-\mathrm{I}$ and 1 equiv. of $\mathrm{HClO}_{4}$ as the co-catalyst. ${ }^{19,21}$ They rationalized the effect of the co-catalyst in terms of the in situ generation of a catalytically active diprotonated form of $\mathbf{I}$, $\mathrm{TBA}_{3}\left[\gamma-\mathrm{PW}_{10} \mathrm{O}_{38} \mathrm{~V}_{2}(\mu-\mathrm{OH})_{2}\right]\left(\mathrm{TBA}_{3} \mathrm{H}_{2}-\mathrm{I}\right){ }^{19}$ To minimize the use of the acid co-catalyst, we attempted to develop a simple and affordable procedure for the preparation of a TBA salt of polyanion I that would contain an increased amount of protons as counter cations. Some modifications of the previously reported synthetic procedure, ${ }^{22}$ viz. additional acidification of the reaction mixture ( $\mathrm{pH} 0.8$ versus $\mathrm{pH} 2.0$ used for the preparation of $\mathrm{TBA}_{4} \mathrm{H}-\mathrm{I}$ ) before final precipitation with $\mathrm{TBABr}$ (see Experimental for details), allowed us to obtain POM with an increased amount of protons (1.5-1.7 $\mathrm{H}^{+}$per POM molecule). IR spectroscopy corroborated the retention of the polyanion structure (Fig. S1†). In dry dilute MeCN solution, such POM revealed two separate ${ }^{31} \mathrm{P}$ NMR signals at -13.7 and -14.1 ppm, which according to the literature, ${ }^{22}$ can be assigned to di- and monoprotonated forms, $\mathrm{TBA}_{3} \mathrm{H}_{2}-\mathbf{I}$ and $\mathrm{TBA}_{4} \mathrm{H}-\mathrm{I}$, respectively. Fig. 1 shows a typical ${ }^{31} \mathrm{P}$ NMR spectrum where the ratio of the two signals is $c a .2: 1$, which implies the formulation of $\mathrm{TBA}_{3.3} \mathrm{H}_{1.7}$-I. The corresponding ${ }^{51} \mathrm{~V}$ NMR spectrum revealed two poorly resolved signals at $-579\left(\mathrm{TBA}_{3} \mathrm{H}_{2}-\mathrm{I}\right)$ and $-581\left(\mathrm{TBA}_{4} \mathrm{H}-\mathrm{I}\right)$ ppm (Fig. S2 in $\left.\mathrm{ESI}_{\dagger} \dagger\right)$. In more concentrated or wet solutions only one averaged NMR signal is observed at $-13.9\left({ }^{31} \mathrm{P}\right)$ and $-579\left({ }^{51} \mathrm{~V}\right)$ due to fast exchange on the NMR time scale. Potentiometric titration with aqueous TBAOH confirmed the presence of two types of acid protons in the POM and made possible accurate determination of the

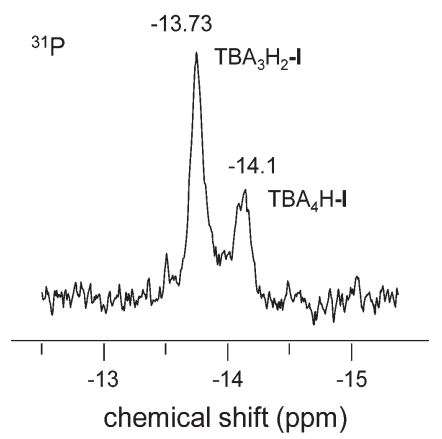

Fig. $1{ }^{31} \mathrm{P}$ NMR spectrum of $\mathrm{TBA}_{3.3} \mathrm{H}_{1.7}-\mathrm{I}(0.0015 \mathrm{M})$ in dry $\mathrm{CH}_{3} \mathrm{CN}$. 
ratio between the two forms of I. Fig. S3† depicts a representative potentiometric titration curve for the sample of $\mathrm{TBA}_{3.5} \mathrm{H}_{1.5}$-I. The results of the potentiometric titration are in good agreement with $\mathrm{CNH}$ analysis (see Experimental).

It is noteworthy that $\mathrm{TBA}_{3.5} \mathrm{H}_{1.5}$-I itself is able to convert TMT to $\mathrm{CoQ}_{0}$ with selectivity as high as $83 \%$ (Table 1 , entry 3 ). However, arene conversion was only $36 \%$ and could not be increased by increasing the reaction time. The addition of $\mathrm{HClO}_{4}$ led to improvement in both substrate conversion and $\mathrm{CoQ}_{0}$ yield. The optimal amount of acid turned out to be close to 0.5 equiv. (Table 1 , compare entries 4-6), corroborating the above mentioned hypothesis that the role of an acid co-catalyst is to generate $\mathrm{TBA}_{3} \mathrm{H}_{2}-\mathrm{I}$ in the diprotonated form.

Fig. 2 demonstrates how the protonation state of $\mathbf{I}$ affects its catalytic performance. Both TMT conversion and $\mathrm{CoQ}_{0}$ yield increase with increasing amounts of protons in the catalyst. In the presence of $\mathrm{TBA}_{3} \mathrm{H}_{2}-\mathrm{I}, 73 \%$ selectivity could be attained at $68 \%$ TMT conversion. Importantly, a similar result was acquired using either $\mathrm{TBA}_{3.5} \mathrm{H}_{1.5}$-I and 0.5 equiv. of $\mathrm{HClO}_{4}$ or $\mathrm{TBA}_{3.3} \mathrm{H}_{1.7}-\mathrm{I}$ and 0.3 equiv. of $\mathrm{HClO}_{4}$, indicating that it does not matter what is the source of protons, POM or mineral acid. Given that the synthesis of $\mathrm{TBA}_{3.5} \mathrm{H}_{1.5}-\mathrm{I}$ is more simple and reproducible than the synthesis of $\mathrm{TBA}_{3} \mathrm{H}_{2}-\mathrm{I}$ (see Experimental for details), we performed further studies and optimization of the catalyst system using $\mathrm{TBA}_{3.5} \mathrm{H}_{1.5}-\mathrm{I}$.

To verify the uniqueness of polyanion $\mathbf{I}$ in the oxidation of TMT, we compared the catalytic performance of $\mathrm{TBA}_{3.5} \mathrm{H}_{1.5}-\mathrm{I}$ with some other representative POMs, including a Si-containing analog, $\mathrm{TBA}_{4} \mathrm{H}_{2}\left[\gamma\right.$-SiW $\left.{ }_{10} \mathrm{~V}_{2} \mathrm{O}_{40}\right]$, and conventional $\alpha$-Keggin heteropoly acids, such as vanadium-free $\mathrm{H}_{3} \mathrm{PW}_{12} \mathrm{O}_{40}$ and divanadium-substituted $\mathrm{H}_{5} \mathrm{PMo}_{10} \mathrm{~V}_{2} \mathrm{O}_{40}$ (the latter has two vanadium atoms statistically distributed over 12 positions of the $\alpha$-Keggin structure). A comparison of their catalytic properties is shown in Fig. 3. One can see that both the Si-analogue of $\mathbf{I}$ and the heteropoly acids are poor catalysts for the production of $\mathrm{CoQ}_{0}$. Although $35-60 \%$ conversion of TMT was attained after $1 \mathrm{~h}$, selectivity towards ubiquinone 0 did not

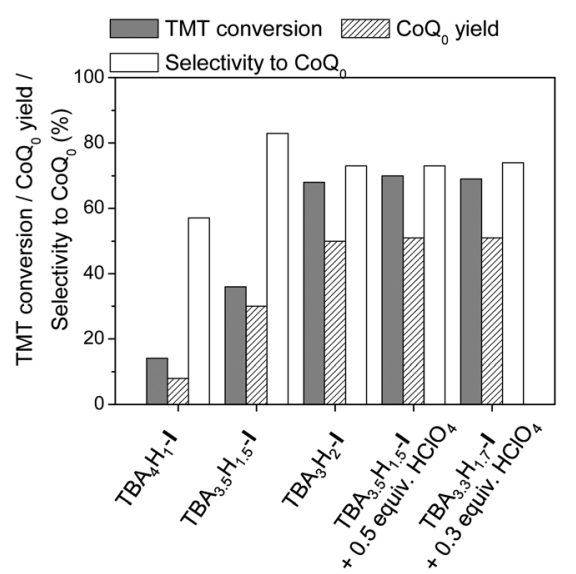

Fig. 2 TMT oxidation in the presence of $\mathrm{TBA}_{5-n} \mathrm{H}_{n}-\mathrm{I}$. Reaction conditions: TMT (0.1 M), $\mathrm{H}_{2} \mathrm{O}_{2}(0.2 \mathrm{M}), \mathrm{I}(2.5 \mathrm{mM}), \mathrm{MeCN} 1 \mathrm{~mL}, 60{ }^{\circ} \mathrm{C}$, $30 \mathrm{~min}$.

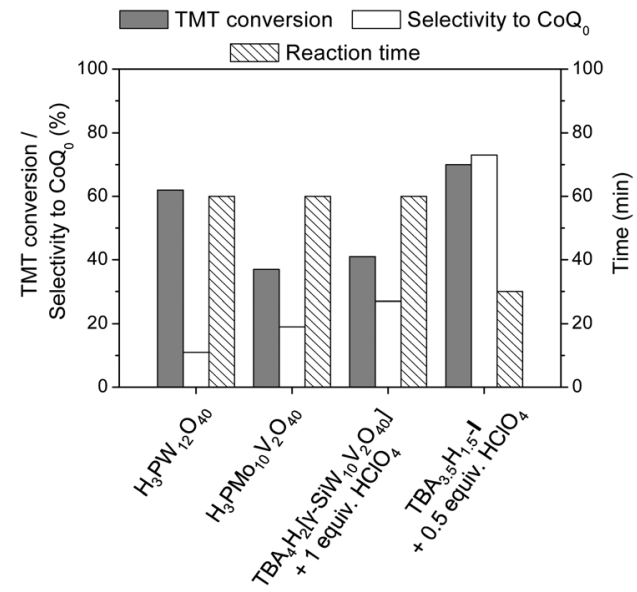

Fig. 3 TMT oxidation in the presence of different POMs. Reaction conditions: TMT (0.1 M), $\mathrm{H}_{2} \mathrm{O}_{2}(0.2 \mathrm{M}), \mathrm{POM}(2.5 \mathrm{mM}), \mathrm{MeCN} 1 \mathrm{~mL}, 60^{\circ} \mathrm{C}$.

exceed $27 \%$. On the other hand, $73 \%$ selectivity at $70 \%$ TMT conversion was reached after $0.5 \mathrm{~h}$ in the presence of $2.5 \mathrm{~mol} \%$ of $\mathrm{TBA}_{3.5} \mathrm{H}_{1.5}$-I combined with 0.5 equiv. of mineral acid. These results indicate that the presence of both the dimeric vanadium core and the $\mathrm{P}$ central atom in the specific $\gamma$-Keggin structure are imperative for efficient catalysis of the title reaction. A simple vanadium complex, $\mathrm{VO}(\mathrm{acac})_{2}$, revealed $42 \%$ TMT conversion in $5 \mathrm{~min}$, but the yield of $\mathrm{CoQ}_{0}$ was below $2 \%$.

To figure out optimal reaction conditions, we studied the influence of all reaction parameters on TMT conversion and $\mathrm{CoQ}_{0}$ selectivity. The results are presented in Table 2 . Previously, it was shown that I-based oxidation of alkylarenes gave better yields of oxygenated products in a solvent mixture of $\mathrm{MeCN}$ and $t \mathrm{BuOH}(1: 1, \mathrm{v} / \mathrm{v}) .{ }^{19,21}$ However, in the case of TMT, the addition of $t$-BuOH resulted in worsening of both arene conversion and quinone selectivity relative to the reaction in MeCN (Table 2, compare entries 1 and 2).

Table 2 TMT oxidation in the presence of $\mathrm{TBA}_{3.5} \mathrm{H}_{1.5}-\mathrm{I}^{\mathrm{a}}$

\begin{tabular}{llllll}
\hline Entry & Cat: TMT $: \mathrm{H}_{2} \mathrm{O}_{2}$ & $\begin{array}{l}\text { TMT } \\
(\mathrm{M})\end{array}$ & $\begin{array}{l}\text { Time } \\
(\mathrm{min})\end{array}$ & $\begin{array}{l}\text { TMT } \\
\text { conv. }(\%)\end{array}$ & $\begin{array}{l}\text { CoQ } \\
\text { select. }^{b}(\%)\end{array}$ \\
\hline 1 & $0.025: 1: 2$ & 0.1 & 30 & 70 & $73(67)^{c}$ \\
$2^{d}$ & $0.025: 1: 2$ & 0.1 & 15 & 43 & 56 \\
$3^{e}$ & $0.025: 1: 2$ & 0.1 & 240 & 39 & 77 \\
$4^{f}$ & $0.025: 1: 2$ & 0.1 & 5 & 71 & 66 \\
5 & $0.013: 1: 2$ & 0.1 & 30 & 69 & 70 \\
6 & $0.05: 1: 2$ & 0.1 & 5 & 66 & 64 \\
7 & $0.025: 1: 2$ & 0.05 & 45 & 75 & 67 \\
8 & $0.025: 1: 2$ & 0.2 & 15 & 51 & 75 \\
9 & $0.025: 1: 3$ & 0.1 & 15 & 65 & 63 \\
$10^{g}$ & $0.025: 1: 3$ & 0.1 & 45 & 85 & 64 \\
$11^{h}$ & $0.025: 1: 2$ & 0.1 & 30 & 76 & 73 \\
$12^{i}$ & $0.025: 1: 2$ & 0.1 & 30 & 64 & 65
\end{tabular}

${ }^{a}$ Reaction conditions: $\mathrm{HClO}_{4}(1.25 \mathrm{mM}), \mathrm{MeCN} 1 \mathrm{~mL}, 60{ }^{\circ} \mathrm{C} .{ }^{b} \mathrm{GC}$ yield based on converted TMT. ${ }^{c}$ Isolated yield. ${ }^{d} \mathrm{MeCN} / t-\mathrm{BuOH}(1: 1, \mathrm{v} / \mathrm{v})$ instead of MeCN. ${ }^{e} 30{ }^{\circ} \mathrm{C} .{ }^{f} 80{ }^{\circ} \mathrm{C}$. ${ }^{g} \mathrm{H}_{2} \mathrm{O}_{2}$ added in three portions. ${ }^{h} \mathrm{H}_{2} \mathrm{O}_{2}$ added in two portions. ${ }^{i} 0.1 \mathrm{M}$ of $\mathrm{MeOH}$ was added. 
The oxidation rate was reduced significantly by decreasing the reaction temperature: after $4 \mathrm{~h}$ at $30^{\circ} \mathrm{C}$, TMT conversion reached only $39 \%$. However, some enhancement in the $\mathrm{CoQ}_{0}$ selectivity was observed (Table 2, compare entries 1 and 3). At $80{ }^{\circ} \mathrm{C}$, the attainable level of conversion was the same as at $60{ }^{\circ} \mathrm{C}$, but selectivity to $\mathrm{CoQ}_{0}$ decreased to $66 \%$ (Table 2, entry 4 ). A 2 -fold reduction of the catalyst concentration with simultaneous alteration of the co-catalyst amount did not strongly affect the catalytic performance (Table 2, compare entries 1 and 5). On the other hand, a 2 -fold augmentation of the catalyst concentration led to some decrease of TMT conversion and $\mathrm{CoQ}_{0}$ selectivity (Table 2, entry 6). A proportional diminution of concentrations of all the reactants relative to the standard conditions resulted in some increase of TMT conversion but led to a reduction in $\mathrm{CoQ}_{0}$ selectivity (Table 2, entry 7). Oppositely, only 51\% substrate conversion was reached in a more concentrated reaction mixture, showing a similar level of selectivity (Table 2, compare entries 1 and 8).

According to the reaction stoichiometry (see Scheme 2), two equivalents of $\mathrm{H}_{2} \mathrm{O}_{2}$ are required to convert TMT to $\mathrm{CoQ}_{0}$. However, under the standard reaction conditions of entry 1 (Table 2), the reaction stopped after $30 \mathrm{~min}$, reaching a substrate conversion of $70 \%$. Semiquantitative evaluation with Quantofix peroxide test sticks revealed that practically no oxidant was present in the final reaction mixture. Therefore, incomplete TMT conversion with 2 equiv. of $\mathrm{H}_{2} \mathrm{O}_{2}$ may be an indication of some unproductive decomposition of the oxidant. When the concentration of $\mathrm{H}_{2} \mathrm{O}_{2}$ was reduced twice relative to the required stoichiometric amount, the oxidant utilization efficiency was improved considerably (70\% versus $52 \%$ ) along with selectivity to the target quinone (82\% versus $73 \%$ ). Fig. 4 shows that $\mathrm{H}_{2} \mathrm{O}_{2}$ efficiency tends to decrease with increasing $\mathrm{H}_{2} \mathrm{O}_{2}$ concentration. The reaction selectivity follows a similar trend. A stepwise addition of the oxidant to the reaction mixture allowed higher TMT conversions to be achieved, keeping quinone selectivity at the same level (Table 2, compare entries 9 and 10, 1 and 11).

During the reaction course, we revealed the formation of a product that reached a maximum yield of $c a .15 \%$ at the initial

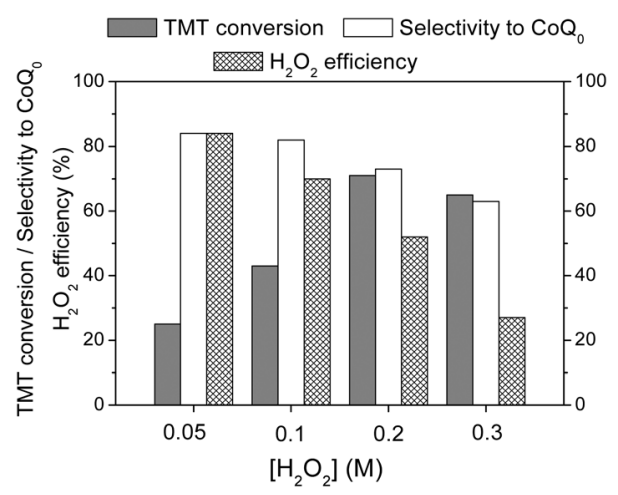

Fig. 4 The effect of $\mathrm{H}_{2} \mathrm{O}_{2}$ concentration on TMT oxidation in the presence of TBA ${ }_{3.5} \mathrm{H}_{1.5}-$ I. Reaction conditions: TMT (0.1 M), I (2.5 mM), $\mathrm{HClO}_{4}$ (1.25 mM), MeCN $1 \mathrm{~mL}, 60^{\circ} \mathrm{C}$.

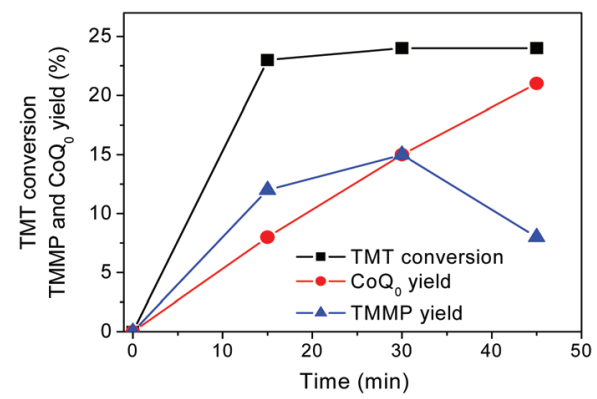

Fig. 5 TMT consumption and product formation versus time. Reaction conditions: TMT (0.1 M), $\mathrm{H}_{2} \mathrm{O}_{2}(0.05 \mathrm{M}), \mathrm{TBA}_{3.5} \mathrm{H}_{1.5} \mathrm{I}(2.5 \mathrm{mM}), \mathrm{HClO}_{4}$ (1.25 mM), MeCN $1 \mathrm{~mL}, 40^{\circ} \mathrm{C}$.

stage and then disappeared (Fig. 5). In the final reaction mixture, only $1-2 \%$ of this compound was detected. GC-MS analysis identified it as 2,3,4-trimethoxy-6-methylphenol (TMMP). The bell-shaped accumulation curve depicted in Fig. 5 suggests that TMMP is, most likely, an intermediate product formed during the conversion of TMT to CoQ ${ }_{0}$. GC-MS also detected trace amounts of a compound that could be assigned to 3,4-dimethoxy-6-methylpyrocatechol or 2,3dimethoxy-6-methyl-hydroquinone. These facts strongly support a mechanism that involves electrophilic hydroxylation of TMT to form TMMP at the first step of the oxidation process (Scheme 3).

At high conversions, $\mathrm{CoQ}_{0}$ was the only product detected by GC, GC-MS, and ${ }^{1} \mathrm{H}$ NMR. However, CoQ yields determined by means of GC or ${ }^{1} \mathrm{H}$ NMR using the internal standard suggested the presence of some by-products, most likely, tars.

To examine reusability of $\mathrm{TBA}_{3.5} \mathrm{H}_{1.5}$-I in the oxidation of TMT, we performed 3-fold scaled experiments, in which the catalyst was separated from the reaction mixture by precipitation with diethyl ether and used repeatedly under the conditions of entry 1 , Table 2 . The recycling performance is shown in Fig. 6. Only minor reduction of arene conversion and product selectivity was observed during at least four recycles. Importantly, the reaction time did not increase, indicating stable catalytic activity. The FTIR spectrum of the recovered catalyst confirmed the retention of the POM structure (see Fig. S1†).

Some decrease of TMT conversion and product yield might be caused by a partial transformation of the POM catalyst to a methoxy derivative, $\left(\mathrm{Bu}_{4} \mathrm{~N}\right)_{3}\left[\gamma-\mathrm{PW}_{10} \mathrm{O}_{38} \mathrm{~V}_{2}(\mu-\mathrm{OH})(\mu-\mathrm{OMe})\right]$, that could be formed during the reaction course upon interaction of polyanion I with methanol, which is one of the reaction pro-

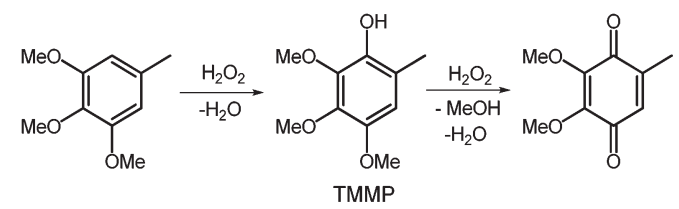

Scheme 3 Plausible route of TMT oxidative transformation to $\mathrm{CoQ}_{0}$. 


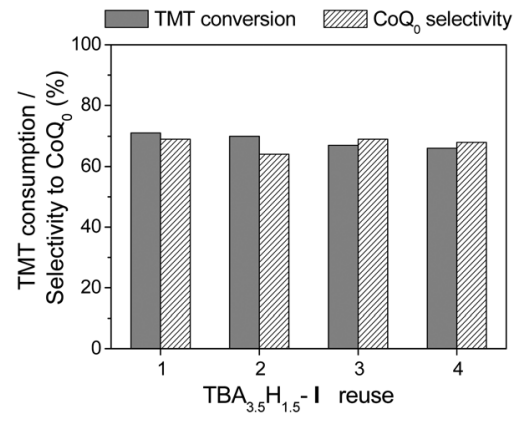

Fig. 6 Reuse of $\mathrm{TBA}_{3.5} \mathrm{H}_{1.5} \mathrm{-I}$ in TMT oxidation. Reaction conditions: TMT (0.1 M), $\mathrm{H}_{2} \mathrm{O}_{2}(0.2 \mathrm{M}), \mathrm{TBA}_{3.5} \mathrm{H}_{1.5} \mathrm{-I}(2.5 \mathrm{mM}), \mathrm{HClO}_{4}(1.25 \mathrm{mM})$, $\mathrm{MeCN}(3 \mathrm{~mL}), 60^{\circ} \mathrm{C}, 15 \mathrm{~min}$.

ducts (see Scheme 2). Earlier, Nakagawa et al. studied the interaction of methanol and other alcohols with the Sicontaining analogue of $\mathbf{I}$ and proved the formation of such methoxy derivatives. ${ }^{23}$ Indeed, ${ }^{51} \mathrm{~V}$ NMR detected the appearance of a signal at $-562 \mathrm{ppm}$ during the reaction progress, which could be assigned to the methoxy derivative of $\mathbf{I}$ (Fig. 7b). To verify this hypothesis, we performed an experiment where 1 equiv. of $\mathrm{MeOH}$ was added to a solution of $\mathrm{TBA}_{3.5} \mathrm{H}_{1.5}$-I in MeCN. Indeed, the appearance of the ${ }^{51} \mathrm{~V}$ NMR signal at $-562 \mathrm{ppm}$ was detected (Fig. 7c). The addition of methanol to the initial reaction mixture produced a rateretarding effect (Fig. 8) and decreased TMT conversion and selectivity to $\mathrm{CoQ}_{0}$ (Table 2, entry 12). It should be noted, however, that most of the methoxy derivative was hydrolyzed back to I upon the recycling workup since the recovered POM

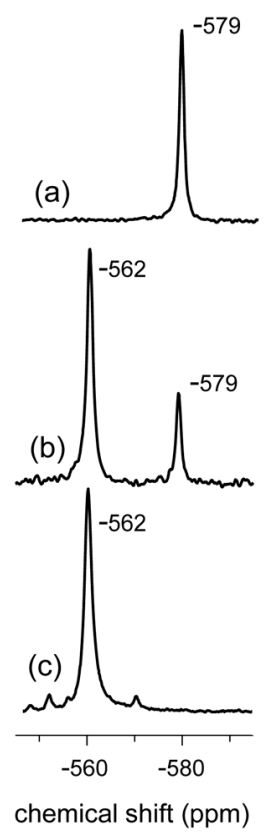

Fig. $7{ }^{51} \mathrm{~V}$ NMR spectra in $\mathrm{CH}_{3} \mathrm{CN}$ : (a) initial $\mathrm{TBA}_{3.5} \mathrm{H}_{1.5} \mathrm{I}$ ( $(0.0025 \mathrm{M})$, (b) reaction mixture after $10 \mathrm{~min}$, and (c) $\mathrm{TBA}_{3.5} \mathrm{H}_{1.5}-\mathrm{I}(0.0025 \mathrm{M})+1$ equiv. of $\mathrm{MeOH}$.

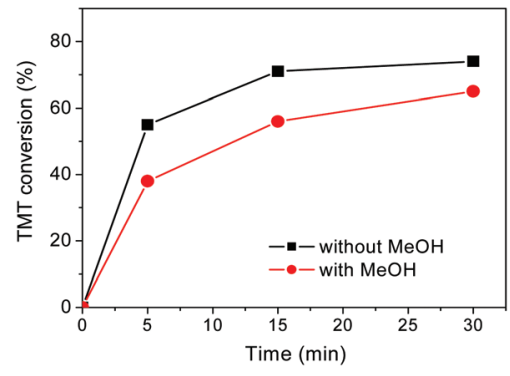

Fig. 8 The effect of $\mathrm{MeOH}$ on TMT conversion. Reaction conditions: TMT (0.1 M), $\mathrm{H}_{2} \mathrm{O}_{2}(0.2 \mathrm{M}), \mathrm{TBA}_{3.5} \mathrm{H}_{1.5} \mathrm{-I}(2.5 \mathrm{mM}), \mathrm{HClO}_{4}$ (1.25 mM), $[\mathrm{MeOH}] 0.1 \mathrm{M}, \mathrm{MeCN} 1 \mathrm{~mL}, 60^{\circ} \mathrm{C}$.

was present in its initial state $(\delta-579 \mathrm{ppm})$. Therefore, ${ }^{31} \mathrm{P}$ and ${ }^{51} \mathrm{~V}$ NMR along with FTIR spectroscopic technique confirmed the retention of the $\gamma$-Keggin structure of $\mathbf{I}$ after the catalysis.

To estimate the scope of the $\mathrm{TBA}_{3.5} \mathrm{H}_{1.5}-\mathrm{I} / \mathrm{H}_{2} \mathrm{O}_{2}$ catalytic system, we studied the oxidation of some other representative methoxyarenes (Scheme 4). The results are summarized in Table 3. For all substrates, the formation of the corresponding quinones occurred with moderate to good yields $(22-70 \%)$ at conversions $\geq 74 \%$. It is noteworthy that the oxidation of $1,2,3-$ trimethoxybenzene (Scheme 4, d) gave only 2,3-dimethoxy-1,4benzoquinone while, for $\mathrm{K}_{3}\left[\mathrm{Fe}(\mathrm{CN})_{6}\right]$-catalyzed $^{8}$ and non-catalytic $^{9}$ oxidations, the formation of two isomeric quinones, 2,3and 2,6-dimethoxy-1,4-benzoquinone, was observed. This fact implies that steric factors, most likely, control the oxidation process in the case of the bulky divanadium-POM catalyst.

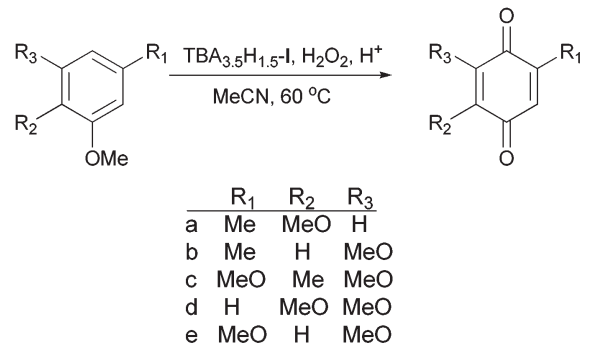

Scheme 4 Oxidation of methoxyarenes in the presence of $\mathrm{TBA}_{3.5} \mathrm{H}_{1.5}-\mathrm{I}$.

Table 3 Oxidation of methoxyarenes catalyzed by $\mathrm{TBA}_{3.5} \mathrm{H}_{1.5}-\mathrm{I}^{\mathrm{a}}$

\begin{tabular}{llll}
\hline Entry & Substrate & Conversion $[\%]$ & Selectivity to quinone ${ }^{b}[\%]$ \\
\hline 1 & a & 92 & 76 \\
2 & b & 81 & 59 \\
3 & c & 74 & 39 \\
4 & d & 82 & 27 \\
5 & e & 77 & 56
\end{tabular}

${ }^{a}$ Reaction conditions: Arene $(0.1 \mathrm{M}), \mathrm{H}_{2} \mathrm{O}_{2}(0.2 \mathrm{M}), \mathrm{TBA}_{3.5} \mathrm{H}_{1.5}$-I (2.5 mM), $\mathrm{HClO}_{4}(1.25 \mathrm{mM}), \mathrm{MeCN} 1 \mathrm{~mL}, 60^{\circ} \mathrm{C}, 5-30 \mathrm{~min} .{ }^{b}$ Based on the converted substrate. 


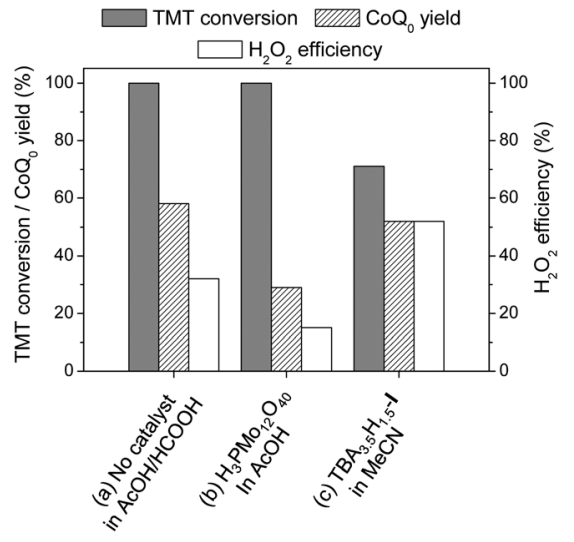

Fig. 9 Comparison of I-catalyzed TMT oxidation with reported systems. Reaction conditions: (a) TMT (1.4 M), $\mathrm{H}_{2} \mathrm{O}_{2}(5.5 \mathrm{M})$ added dropwise for $10 \mathrm{~min}, \mathrm{HCOOH} 0.35 \mathrm{~mL}, \mathrm{AcOH} 0.18 \mathrm{~mL}, 35^{\circ} \mathrm{C}$; (b) TMT (2.2 M), $50 \%$ $\mathrm{H}_{2} \mathrm{O}_{2}(7 \mathrm{M}), \mathrm{H}_{3} \mathrm{PMO}_{12} \mathrm{O}_{40}(0.7 \mathrm{M}), \mathrm{HCOOH} 0.5 \mathrm{~mL}, 25^{\circ} \mathrm{C}$; and (c) as in Table 2, entry 1 .

For the sake of comparison, we also performed TMT oxidation following two protocols reported in the literature ${ }^{14,16}$ but in a lower scale $(1 \mathrm{~mL})$. The comparison is shown in Fig. 9. In a mixture of formic and acetic acids, CoQ 0 yield achieved $58 \%$, which is a bit higher than the yield obtained in the presence of $\mathrm{TBA}_{3.5} \mathrm{H}_{1.5} \mathrm{I}$ ( $\left.52 \%\right)$. On the contrary, the quinone yield was significantly lower (ca. 30\%) in the presence of phosphomolybdic acid in AcOH. An evident advantage of the $\mathrm{TBA}_{3.5} \mathrm{H}_{1.5}$-I-based catalyst system is greater oxidant utilization efficiency (see Fig. 9), which allows one to attain a good product yield using just the stoichiometric amount of the oxidant. In addition, we avoid the use of carboxylic acids as solvents and, therefore, preclude corrosion and formation of explosive peroxy acids upon interaction with $\mathrm{H}_{2} \mathrm{O}_{2}$.

\section{Conclusions}

In summary, we have developed a new method for the synthesis of the important fine chemical coenzyme $Q_{0}$ via oxidation of commercially available 3,4,5-trimethoxytoluene with $30 \% \mathrm{H}_{2} \mathrm{O}_{2}$ in MeCN employing acid tetrabutylammonium salts of the divanadium-substituted polyoxometalate $\left[\gamma-\mathrm{PW}_{10} \mathrm{~V}_{2} \mathrm{O}_{40}\right]^{5-}$ as a catalyst. Coenzyme $\mathrm{Q}_{0}$ was obtained with selectivity as high as $73 \%$ at $76 \%$ arene conversion. The procedure is affordable, safe and sustainable. The catalyst system is applicable to oxidation of a variety of di- and trimethoxyarenes, producing the corresponding benzoquinones in moderate to good yields. Since the presence of an acid is crucial for the catalytic performance, a simple procedure for the preparation of a highly protonated derivative $\mathrm{TBA}_{3.5} \mathrm{H}_{1.5}$-I has been developed. The use of this derivative enables significant reduction of the amount of acid co-catalyst without deterioration of the catalytic performance. The catalyst could be easily separated from the reaction mixture and recycled without appreciable loss of activity and selectivity.

\section{Experimental}

\section{Materials and instrumentation}

3,4,5-Trimethoxytoluene (97\%) and 2,3-dimethoxy-5-methyl1,4-benzoquinone (99\%) were obtained from Aldrich, 2,3dimethoxytoluene (98\%) and 2,4,6-trimethoxytoluene (97\%) were purchased from Alfa, 3,5-dimethoxytoluene (99\%), 1,2,3trimethoxybenzene (98\%) and 1,3,5-trimethoxybenzene (99\%) were obtained from Acros. Acetonitrile (Panreac, HPLC grade) was dried and stored over activated $4 \AA$ molecular sieves. All the other compounds were the best available reagent grade and used without further purification. The concentration of $\mathrm{H}_{2} \mathrm{O}_{2}$ (ca. 35 wt\% aqueous solution) was determined iodometrically prior to use. GC analyses were performed using a gas chromatograph Chromos GC-1000 equipped with a flame ionization detector and a quartz capillary column BPX5 $(30 \mathrm{~m}$ $\times 0.25 \mathrm{~mm}$ ). GC-MS analyses were carried out using an Agilent 7000B system with a triple-quadrupole mass-selective detector Agilent 7000 (HP-5 ms quartz capillary column $30 \mathrm{~m} \times$ $0.25 \mathrm{~mm}) .{ }^{1} \mathrm{H},{ }^{31} \mathrm{P}$ and ${ }^{51} \mathrm{~V}$ NMR spectra were recorded on a Brüker AVANCE-400 spectrometer at 400.130, 161.67 and 105.24 MHz, respectively. Chemical shifts for $\mathrm{P}$ and $\mathrm{V}, \delta$, were determined relative to $85 \% \mathrm{H}_{3} \mathrm{PO}_{4}$ and $\mathrm{VOCl}_{3}$, respectively. Infrared spectra were recorded with $\mathrm{KBr}$ pellets on an Agilent 660 FTIR spectrometer.

\section{General catalyst preparation}

$\boldsymbol{\gamma}-\mathbf{C s}_{7} \mathbf{P W}_{\mathbf{1 0}} \mathbf{O}_{\mathbf{3 6}} \cdot \mathbf{5 H}_{\mathbf{2}} \mathbf{O}$. The synthesis of the cesium salt of the dilacunary phosphotungstate was carried out either following the protocol reported in the literature that employs expensive and caustic $\mathrm{CsOH},{ }^{24}$ or using a modified procedure described below. $14.6 \mathrm{~g}$ of $\mathrm{WO}_{3}$ were mixed with $20 \mathrm{~g}$ of anhydrous $\mathrm{Cs}_{2} \mathrm{CO}_{3}$ in a nickel melting pot. A small amount of $\mathrm{Cs}_{2} \mathrm{CO}_{3}$ was added to cover $\mathrm{WO}_{3}$. The mixture was calcined at $620^{\circ} \mathrm{C}$ for $6 \mathrm{~h}$. Then the residue was stored in air overnight. Upon storing, the mixture adsorbs water from air that leads to its swelling and makes it easier to be removed from the melting pot. The solid was mixed with $50 \mathrm{ml}$ of water. The white precipitate was removed by filtration. Firstly, $2 \mathrm{ml}$ of $3.25 \mathrm{M}$ $\mathrm{H}_{3} \mathrm{PO}_{4}(\mathrm{~W}: \mathrm{P}=5 \mathrm{~mol} / \mathrm{mol})$, and then $3 \mathrm{M} \mathrm{HNO}_{3}$ were added to the mother liquor until $\mathrm{pH}$ reached 7 . During the adjustment of the $\mathrm{pH}$ a white precipitate was formed. The mixture was heated to boiling and then filtered. The white solid was separated, washed with hot water and dried. Then another portion of $3 \mathrm{M} \mathrm{HNO}_{3}$ was added to the filtrate until pH reached 7, and a new portion of the white solid was treated as described above. Total yield of $\gamma$-Cs $7 \mathrm{PW}_{10} \mathrm{O}_{36} \cdot 5 \mathrm{H}_{2} \mathrm{O}$ was $c a$. $80 \%$ (17.5 g). The IR spectrum of the obtained solid corresponded to that of $\gamma$-Cs ${ }_{7} \mathrm{PW}_{10} \mathrm{O}_{36} \cdot 5 \mathrm{H}_{2} \mathrm{O}$ prepared by the conventional procedure. ${ }^{24}$ IR (KBr, cm $\left.{ }^{-1}\right):$ 1080, 1050, 1025, 937, 892, 829, 755.

$\mathbf{T B A}_{4} \mathbf{H}$-I. The monoprotonated derivative $\mathrm{TBA}_{4} \mathrm{H}$ $\left[\gamma-\mathrm{PV}_{2} \mathrm{~W}_{10} \mathrm{O}_{40}\right]$ was prepared according to the procedure reported by Kamata et al. ${ }^{22}$ with some modifications reported elsewhere. ${ }^{20}{ }^{51} \mathrm{~V}$ NMR (MeCN): $-581 \mathrm{ppm},{ }^{31} \mathrm{P}$ NMR (MeCN): $-14.1 \mathrm{ppm}$. 
TBA $_{3.5} \mathbf{H}_{1.5}$-I. POM with the increased amount of $\mathrm{H}^{+}$, that is the mixture of mono- and diprotonated forms, $\mathrm{TBA}_{4} \mathrm{H}-\mathrm{I}$ and $\mathrm{TBA}_{3} \mathrm{H}_{2}$-I, having an averaged composition of $\mathrm{TBA}_{3.5} \mathrm{H}_{1.5}-\mathbf{I}$, was prepared according to the following procedure. $\mathrm{NaVO}_{3} \cdot 2 \mathrm{H}_{2} \mathrm{O}$ (145 mg) was dissolved in $12 \mathrm{~mL}$ of $\mathrm{H}_{2} \mathrm{O}$ and the $\mathrm{pH}$ of the solution was adjusted to 0.8 with $3 \mathrm{M} \mathrm{HCl}$. Then $\mathrm{Cs}_{7}\left[\gamma-\mathrm{PW}_{10} \mathrm{O}_{36}\right] \cdot 5 \mathrm{H}_{2} \mathrm{O}(1.3 \mathrm{~g})$ was added to the solution, and a yellow precipitate was formed. The mixture was diluted with $20 \mathrm{~mL}$ of $\mathrm{H}_{2} \mathrm{O}$ and the $\mathrm{pH}$ of the solution was again adjusted to 0.8 with $3 \mathrm{M} \mathrm{HCl}$. After separation of an insoluble residue by filtration, TBABr $(474 \mathrm{mg})$ was added to the liquor. A yellow precipitate was separated, washed with water and dried in air. Potentiometric titration with TBAOH $\left(0.39 \mathrm{M}\right.$ in $\left.\mathrm{H}_{2} \mathrm{O}\right)$ revealed the presence of $c a$. 1.5 acid protons per anion I. CHN analysis calcd (\%) for $\mathrm{TBA}_{3.5} \mathrm{H}_{1.5}\left[\mathrm{PV}_{2} \mathrm{~W}_{10} \mathrm{O}_{40}\right]$ : $\mathrm{C}$ 19.4, $\mathrm{H}$ 3.7, $\mathrm{N}$ 1.4; found: $\mathrm{C}$ 19.1, $\mathrm{H}$ 3.45, N 1.4. ${ }^{51} \mathrm{~V}$ NMR (MeCN, $\left.0.005 \mathrm{M}\right)$ : -579 ppm; ${ }^{31} \mathrm{P}$ NMR (MeCN): $-13.9 \mathrm{ppm}$. IR $\left(\mathrm{KBr}, \mathrm{cm}^{-1}\right)$ : 1623, 1481, 1380, 1097, 1061, 1039, 964, 911, 876, 805, 700, 535.

$\mathbf{T B A}_{3} \mathbf{H}_{2}$-I. The diprotonated derivative $\mathrm{TBA}_{3}\left[\gamma-\mathrm{H}_{2} \mathrm{PV}_{2} \mathrm{~W}_{10} \mathrm{O}_{40}\right]$ was prepared according to the reported procedure: ${ }^{22}$ $\mathrm{TBA}_{4}\left[\gamma-\mathrm{HPV}_{2} \mathrm{~W}_{10} \mathrm{O}_{40}\right](150 \mathrm{mg})$ was dissolved in $2 \mathrm{ml}$ of MeCN and 1 equiv. of $\mathrm{HClO}_{4}$ was added to the solution. The mixture was diluted with $20 \mathrm{ml}$ of diethyl ether. After precipitation of an yellow oil, the mother liquor was separated. The oil was dried under vacuum to obtain yellow crystals of $\mathrm{TBA}_{3} \mathrm{H}_{2}-\mathrm{I} .{ }^{51} \mathrm{~V}$ NMR (MeCN): -579 ppm, ${ }^{31} \mathrm{P}$ NMR (MeCN): -13.7 ppm. IR $\left(\mathrm{KBr}, \mathrm{cm}^{-1}\right):$ 1630, 1480, 1380, 1090, 1062, 1042, 1015, 967, $876,805,700,536$. It should be noted, however, that scaling up of this synthesis protocol to obtain a sufficient quantity of crystalline $\mathrm{TBA}_{3} \mathrm{H}_{2}$-I was not successful.

Other POMs. $\mathrm{TBA}_{4}\left[\gamma-\mathrm{SiW}_{10} \mathrm{O}_{38} \mathrm{~V}_{2}(\mu-\mathrm{OH})_{2}\right]$ was synthesized following the protocol described by Nakagawa et al. ${ }^{25}$ Heteropolyacid $\mathrm{H}_{5} \mathrm{PMo}_{10} \mathrm{~V}_{2} \mathrm{O}_{40}$ was prepared according to the literature. $^{26}$

\section{General methods for catalytic oxidation and product analysis}

TMT oxidation. Catalytic oxidations of TMT with $\mathrm{H}_{2} \mathrm{O}_{2}$ in the presence of $\mathrm{TBA}_{4} \mathrm{H}-\mathrm{I}$ or $\mathrm{TBA}_{3.5} \mathrm{H}_{1.5}-\mathrm{I}$ were carried out in temperature-controlled glass vessels at $30-80{ }^{\circ} \mathrm{C}$ under vigorous stirring $(500 \mathrm{rpm})$. Concentrations of the reactants were in the range of $[\mathrm{TMT}]=0.05-0.2,[\mathrm{I}]=0.0013-0.05,\left[\mathrm{HClO}_{4}\right]=$ 0-0.025, and $\left[\mathrm{H}_{2} \mathrm{O}_{2}\right]=0.1-0.45 \mathrm{M}$. Typically, the reactions were initiated by the addition of $\mathrm{H}_{2} \mathrm{O}_{2}$ either in one portion or stepwise to a mixture containing an aromatic substrate, $\mathbf{I}, \mathrm{HClO}_{4}$, and an internal standard in $1 \mathrm{~mL}$ of a solvent (MeCN or its mixture with $t$-BuOH). Samples were taken during the reaction course by using a syringe and analyzed. The oxidation products were identified by GC, GC-MS and ${ }^{1} \mathrm{H}$ NMR using authentic samples. The substrate conversions and product yields were quantified by GC using chlorobenzene as the internal standard. Each experiment was reproduced at least two times. The experimental error in the determination of substrate conversions and product yields by GC normally did not exceed $2 \%$. Semiquantitative Quantofix peroxide test sticks were used for estimating the amount of $\mathrm{H}_{2} \mathrm{O}_{2}$ at the end of catalytic reac- tions. The catalyst reusability was examined in 3-fold scaled experiments (the total reaction mixture volume $3 \mathrm{~mL}$ ). The catalyst was separated from the reaction mixture by precipitation with diethyl ether, dried in air and used repeatedly with the next portion of the reagents. To isolate the ubiquinone product, the reaction mixture was diluted with water followed by extraction with $\mathrm{CH}_{2} \mathrm{Cl}_{2}$. After concentration under vacuum at room temperature, pure $\mathrm{CoQ}_{0}$ was isolated by preparative column chromatography on silica gel using gradient elution with hexane and hexane/ethyl acetate. The ${ }^{1} \mathrm{H}$ NMR spectrum of the isolated product (Fig. S4 in ESI $\dagger$ ) was identical to that of the authentic sample. The vanadium content in the isolated product was below the detection limit of ICP-AES analysis.

Oxidation of methoxyarenes. Catalytic oxidations of various methoxyarenes with $\mathrm{H}_{2} \mathrm{O}_{2}$ in the presence of $\mathrm{TBA}_{3.5} \mathrm{H}_{1.5}-\mathrm{I}$ were carried out in temperature-controlled glass vessels at $60{ }^{\circ} \mathrm{C}$ under vigorous stirring (500 rpm). Concentrations of the reactants were as follows: [substrate] $=0.1,\left[\mathrm{TBA}_{3.5} \mathrm{H}_{1.5}-\mathrm{I}\right]=0.0025$, $\left[\mathrm{HClO}_{4}\right]=0.00125$, and $\left[\mathrm{H}_{2} \mathrm{O}_{2}\right]=0.2 \mathrm{M}$. The reactions were initiated by the addition of $\mathrm{H}_{2} \mathrm{O}_{2}$ to a mixture containing an aromatic substrate, the $\mathrm{TBA}_{3.5} \mathrm{H}_{1.5}$-I catalyst and $\mathrm{HClO}_{4}$ in $1 \mathrm{~mL}$ of $\mathrm{MeCN}$. The oxidation products were identified by GC-MS and ${ }^{1} \mathrm{H}$ NMR (Fig. S5-S9†). All GC-MS and ${ }^{1} \mathrm{H}$ NMR spectra are in accordance with the reported data. ${ }^{7,8}$ The substrate conversions and product yields were quantified by ${ }^{1} \mathrm{H}$ NMR and/or GC using chlorobenzene as the internal standard. Each experiment was reproduced at least two times.

\section{Product characterization}

2,3-Dimethoxy-5-methyl-1,4-benzoquinone. $\quad{ }^{1} \mathrm{H} \quad$ NMR $\left(400 \mathrm{MHz} ; \mathrm{CDCl}_{3}, 25{ }^{\circ} \mathrm{C}\right): \delta 6.41$ (q, $\left.J=1.9 \mathrm{~Hz}, 1 \mathrm{H}\right) ; 3.91(\mathrm{~s}$, $3 \mathrm{H}) ; 3.89$ (s, 3H); 2.07 (s, 3H). GC-MS (EI): $m / z 182\left(\mathrm{M}^{+}, 25 \%\right)$, 167 (13), 154 (7), 137 (66), 126 (23), 111 (28), 96 (17), 83 (100), 69 (70), 68 (60).

2,3,4-Trimethoxy-6-methylphenol. GC-MS (EI): $m / z 198\left(\mathbf{M}^{+}\right.$, 100\%), 183 (95), 168 (10), 155 (16), 140 (61), 137 (23), 122 (15), 69 (75).

3,4-Dimethoxy-6-methylpyrocatechol (or 2,3-dimethoxy-6methyl-hydroquinone). GC-MS (EI): m/z 184 (M+, 96\%), 169 (100), 154 (15), 141 (19), 137 (13), 126 (60), 123 (27), 69 (85).

2-Methoxy-5-methyl-1,4-benzoquinone. ${ }^{1} \mathrm{H}$ NMR $(400 \mathrm{MHz}$; $\left.\mathrm{CD}_{3} \mathrm{CN}, 25^{\circ} \mathrm{C}\right): \delta 6.52(\mathrm{q}, J=1.6 \mathrm{~Hz}, 1 \mathrm{H}) ; 5.94(\mathrm{~s}, 1 \mathrm{H}) ; 3.75(\mathrm{~s}$, $3 \mathrm{H}) ; 2.07$ (s, 3H). GC-MS (EI): m/z 152 (M , 14\%), 137 (4), 122 (10), 109 (6), 69 (100).

2-Methoxy-6-methyl-1,4-benzoquinone. ${ }^{1} \mathrm{H}$ NMR $(400 \mathrm{MHz}$; $\left.\mathrm{CD}_{3} \mathrm{CN}, 25{ }^{\circ} \mathrm{C}\right): \delta 6.49(\mathrm{~m}, 1 \mathrm{H}) ; 5.89(\mathrm{~d}, J=2.3 \mathrm{~Hz}, 1 \mathrm{H}) ; 3.75(\mathrm{~s}$, $3 \mathrm{H}) ; 2.07$ (s, 3H). GC-MS (EI): m/z 152 (M , 15\%), 137 (4), 124 (17), 122 (13), 109 (11), 69 (100).

2,6-Dimethoxy-3-methyl-1,4-benzoquinone. $\quad{ }^{1} \mathrm{H} \quad \mathrm{NMR}$ $\left(400 \mathrm{MHz} ; \mathrm{CDCl}_{3}, 25{ }^{\circ} \mathrm{C}\right): \delta 5.85(\mathrm{~s}, 1 \mathrm{H}) ; 3.97(\mathrm{~s}, 3 \mathrm{H}) ; 3.80(\mathrm{~s}$, $3 \mathrm{H}) ; 1.97$ (s, 3H). GC-MS (EI): m/z $182\left(\mathrm{M}^{+}, 47 \%\right), 167$ (6), 149 (6), 139 (40), 111 (21), 83 (83), 69 (100).

2,3-Dimethoxy-1,4-benzoquinone. ${ }^{1} \mathrm{H} \quad \mathrm{NMR} \quad(400 \mathrm{MHz}$; $\left.\mathrm{CH}_{3} \mathrm{CN}, 25{ }^{\circ} \mathrm{C}\right): \delta 6.53(\mathrm{~s}, 2 \mathrm{H}) ; 3.86(\mathrm{~s}, 6 \mathrm{H})$. GC-MS (EI): $m / z 168$ (M+12\%), 153 (11), 123 (28), 82 (20), 69 (100). 
2,6-Dimethoxy-1,4-benzoquinone. ${ }^{1} \mathrm{H} \quad \mathrm{NMR} \quad(400 \mathrm{MHz}$; $\left.\mathrm{CDCl}_{3}, 25{ }^{\circ} \mathrm{C}\right): \delta 5.84(\mathrm{~s}, 2 \mathrm{H}) ; 3.81$ (s, 6H). GC-MS (EI): $m / z 168$ (M+24\%), 138 (22), 125 (55), 97 (14), 80 (16), 69 (100).

\section{Acknowledgements}

The authors thank Dr I. E. Soshnikov and Dr M. V. Shashkov for their help with product identification by ${ }^{1} \mathrm{H}$ NMR and GC-MS, respectively. This work was carried out in the framework of budget project no. 0303-2016-0005 for Boreskov Institute of Catalysis and partially supported by the Russian Foundation for Basic Research (RFBR grant 13-03-12042).

\section{References}

1 (a) The Chemistry of the Quinonoid Compounds, ed. S. Patai and Z. Rappoport, Wiley, New York, 1988; (b) K. C. Nicolaou, J. S. Chen, D. J. Edmonds and A. A. Estrada, Angew. Chem., Int. Ed., 2009, 48, 660; (c) O. A. Kholdeeva, in Arene Chemistry: Reaction Mechanisms and Methods for Aromatic Compounds, ed. J. Mortier, Wiley, 2016, ch. 14, pp. 365-398; (d) O. A. Kholdeeva and O. V. Zalomaeva, Coord. Chem. Rev., 2016, 306, 302.

2 L. Ernster and G. Dallner, Biochim. Biophys. Acta, Mol. Basis Dis., 1995, 1271, 195.

3 Coenzyme Q: Molecular Mechanisms in Health and Disease, ed. V. E. Kagan and P. J. Quinn, CRC Press, Boca Raton, FL, 2000.

4 J. C. Gillis, P. Benfield and D. McTavish, Drugs Aging, 1994, 5, 133.

5 (a) V. Berl, F. Wetterich, H. Ernst and K. Schein, WO patent 2006032425, 2006; (b) E. Negishi, S.-Y. Liou, C. Xu and S. Huo, Org. Lett., 2002, 4, 261; (c) B. H. Lipshutz, A. Lower, V. Berl, K. Schein and F. Wetterich, Org. Lett., 2005, 7, 4095. 6 J. Wang, S. Li, T. Yang and J. Yang, Tetrahedron, 2014, 70, 9029.

7 W. Adam and M. Shimizu, Synthesis, 1994, 560.

8 M. Matsumoto, H. Kobayashi and Y. Hotta, J. Org. Chem., 1985, 50, 1766.
9 H. Orita, M. Shimizu, T. Hayakawa and K. Takehira, Bull. Chem. Soc. Jpn., 1989, 62, 1652.

10 H. Sugihara, M. Watanabe, Y. Kawamatsu and H. Morimoto, Justus Liebigs Ann. Chem., 1972, 763, 109.

11 W. Adam, W. A. Herrmann, C. R. Saha-Möller and M. Shimizu, J. Mol. Catal. A: Chem., 1995, 97, 15.

12 R. Bernini, E. Mincione, M. Barontini, G. Fabrizi, M. Pasqualetti and S. Tempesta, Tetrahedron, 2006, 62, 7733.

13 (a) H. Orita, M. Shimizu, T. Hayakawa and K. Takehira, React. Kinet. Catal. Lett., 1991, 44, 209; (b) H. Orita, M. Shimizu, T. Hayakawa and K. Takehira, EP 0347021, 1989.

14 A. S. Chida, P. V. S. N. Vani, M. Chandrasekharam, R. Srinivasan and A. K. Singh, Synth. Commun., 2001, 31, 657.

15 G. Occhipinti, L. Liguori, A. Tsoukala and H.-R. Bjørsvik, Org. Process Res. Dev., 2010, 14, 1379.

16 J. Wang, X. Hu and J. Yang, Synthesis, 2014, 2371.

17 S. Iwasa, A. Fakhruddin, H. S. Widagdo and H. Nishiyama, Adv. Synth. Catal., 2005, 347, 517.

18 M. Crucianelli, R. Saladino and F. De Angelis, ChemSusChem, 2010, 3, 524.

19 K. Kamata, T. Yamaura and N. Mizuno, Angew. Chem., Int. Ed., 2012, 51, 7275.

20 I. D. Ivanchikova, N. V. Maksimchuk, R. I. Maksimovskaya, G. M. Maksimov and O. A. Kholdeeva, ACS Catal., 2014, 4, 2706.

21 O. V. Zalomaeva, V. Yu. Evtushok, G. M. Maksimov and O. A. Kholdeeva, J. Organomet. Chem., 2015, 793, 210.

22 K. Kamata, K. Yonehara, Y. Nakagawa, K. Uehara and N. Mizuno, Nat. Chem., 2010, 2, 478.

23 Y. Nakagawa, K. Uehara and N. Mizuno, Inorg. Chem., 2005, 44, 14.

24 P. J. Domaille, G. Hervé and A. Tézé, in Inorganic Syntheses, ed. A. P. Ginsberg, John Wiley \& Sons, Inc., 1990, vol. 27, pp. 96-104.

25 Y. Nakagawa, K. Kamata, M. Kotani, K. Yamaguchi and N. Mizuno, Angew. Chem., Int. Ed., 2005, 44, 5136.

26 G. A. Tsigdinos and C. J. Hallada, Inorg. Chem., 1968, 7, 437. 